\title{
ENTRE O DESENVOLVIMENTO E A DESIGUALDADE SOCIAL: UMA ANÁLISE DO DISCURSO DE POSSE DOS GOVERNADORES PAULISTAS NO PERÍODO DA DITADURA MILITAR
}

\author{
BETWEEN DEVELOPMENT AND SOCIAL INEQUALITY: \\ AN ANALYSIS OF SPEECH OF POSSESSION OF SÃO \\ PAULO STATE GOVERNORS IN PERIOD OF MILITARY \\ DICTATORSHIP
}

\author{
Vanderlei de Castro Ezequiel ${ }^{*}$
}

\begin{abstract}
RESUMO
O objetivo deste trabalho foi estudar o discurso de posse dos governadores do Estado de São Paulo eleitos indiretamente, ou indicados, durante a ditadura militar brasileira, e analisar o discurso político sobre desenvolvimento e desigualdade, destacando o processo de espetacularização da questão social. Para tanto, utilizou-se a Análise de Discurso de linha francesa (MAINGUENEAU), entendendo o discurso político (CHARAUDEAU) como enunciação de uma época, ou seja, um conjunto de enunciados, ou sequencias discursivas (ORLANDI), que permite identificar os ditos - modos de ver e dizer - em um dado contexto sócio-histórico (SKIDMORE). Dessa forma, este trabalho privilegiou os sentidos dominantes presentes nos discursos de posse, na tentativa de revelar a dicotomia entre desenvolvimento e desigualdade social (NETTO; MESTRINER). As teses da Sociedade do Espetáculo (DEBORD) conduzem a análise crítica do discurso político presente no corpus. Concluiu-se que o discurso de superação das desigualdades sociais como consequência do desenvolvimento da economia faz parte da cena política brasileira no período analisado. Porém, o contexto sócio-político e interesses intrínsecos dos protagonistas imprimem conotações diferenciadas, ou mesmo antagônicas a esses discursos.
\end{abstract}

Palavras-chave: Discurso político. Desenvolvimento. Questão social. Espetacularização.

\begin{abstract}
The purpose of this study was the inaugural Governors of the State of São Paulo indirectly elected, or appointed during the Brazilian military dictatorship, and analyze political discourse on development and inequality, highlighting the process of spectacle of the social question. For this, we used the analysis of French Discourse (MAINGUENEAU), understanding the political discourse (CHARAUDEAU) as enunciation of a time, ie, a set of statements, or discursive sequences (ORLANDI), which identifies said - ways of seeing and saying - in
\end{abstract}

\footnotetext{
* Mestre em Comunicação pela Faculdade Cásper Líbero; Especialista em Comunicação; Especialista em TI; Membro do grupo de pesquisa Comunicação e Sociedade do Espetáculo vinculado à CNPq - contato: vander.ce@gmail.com
} 
a given socio-historical context (SKIDMORE). Thus, this work focused the dominant meanings of the discourse of possession in an attempt to reveal the dichotomy between development and social inequality (NETTO; MESTRINER). The theses of the Society of the Spectacle (DEBORD) lead to critical analysis of this corpus in political discourse. It was concluded that the discourse of overcoming social inequalities as a consequence of economic development is part of the Brazilian political scene in the analyzed period. However, the socio-political context and intrinsic interests of the protagonists print different connotations, or even antagonistic to these speeches.

Keywords: Political discourse. Development. Social issue. Spectacle. Dictatorship.

\section{Introdução}

No Brasil, o combate às seqüelas da "questão social" historicamente oscilou entre o assistencialismo paternalista e ações de repressão aos movimentos reivindicatórios. Tema recorrente na política nacional, a superação das desigualdades sociais é vinculada ao desenvolvimento e crescimento econômico. Assim, perdura no pensamento político dominante a idéia de que a distribuição de renda deve ser precedida do crescimento econômico. Nas palavras de um Ministro da Fazenda da década de 1970: "O bolo deve crescer antes que possamos dividi-lo". Desde então, esta frase tornou-se comum no meio político, revelando um discurso recorrente dos governantes brasileiros.

O objetivo deste texto é, no plano geral, estudar o discurso de posse dos governadores do Estado de São Paulo no período da ditadura militar ${ }^{1}$ e, no plano específico, discutir e analisar, por meio de sequências discursivas, o discurso político sobre desenvolvimento e desigualdade.

Para constituição do corpus - objeto de análise - considerou-se seqüências discursivas dos discursos de posse dos Governadores do Estado de São Paulo, partindo da premissa de que os políticos e empresários paulistas constituíram-se em atores importantes no conturbado período de nossa história, conhecido com ditadura militar. Dessa forma, entende-se que a mensagem do Governador paulista, no ato de sua posse, ultrapassa o âmbito estadual e revela os ditos dominantes na cultura política brasileira.

${ }^{1}$ Discurso de posse dos governadores do Estado de São Paulo desde 1967 até 1978, publicados no Diário Oficial do Estado - DOE.
A principal orientação teórico-metodológica deste trabalho é a Análise de Discurso de linha francesa (MAINGUENEAU), entendendo o discurso político (CHARAUDEAU) como enunciação de uma época, ou seja, um conjunto de enunciados, ou sequencias discursivas (ORLANDI), que permite identificar os ditos - modos de ver e dizer - em um dado contexto sócio-histórico (SKIDMORE). Dessa forma, este trabalho privilegiou os sentidos dominantes presentes nos discursos de posse, na tentativa de revelar a dicotomia entre desenvolvimento e desigualdade social (NETTO; MESTRINER). Sendo assim, busca-se analisar o material coletado na pesquisa documental de modo a deixar que as seqüências discursivas selecionadas falem por si só. Em seguida, foram considerados os gestos de interpretação presentes nesses discursos, ou seja, o modo como os sujeitos enunciadores - no caso, os governadores eleitos - interpretam o momento sócio-histórico em que estão inseridos. As teses da Sociedade do Espetáculo (DEBORD) conduzem a análise crítica do discurso político presente no corpus.

Para composição dos recortes utilizados neste texto, orienta-se pela proposta de Orlandi (2010) que postula que essa delimitação não segue critérios empíricos, mas teóricos ${ }^{2}$. Assim, o corpus se delimita à prática discursiva dos discursos de posse dos governadores paulistas, composto de recortes que permitem constituir sentidos acerca da presença das "questões sociais" na política brasileira.

\footnotetext{
${ }^{2}$ Sabe-se que a escolha de um objeto a ser analisado, utilizando-se a fundamentação teórica da Análise de Discurso, não pode ser aleatória. Dessa forma, os recortes têm que vir com os objetivos propostos pelo analista. Conforme Orlandi (2010), o objeto discursivo não é dado, ele supõe um trabalho inicial do analista. Num primeiro momento de análise, é preciso converter o corpus bruto, empírico em um objeto teórico.
} 


\section{Justificativa do corpus}

A justificativa para a constituição do corpus deve-se, principalmente, pela importância que os políticos e empresários paulistas assumiram nos fatos que culminaram com o golpe militar de 1964, e também na manutenção do governo autoritário.

O chamado "Golpe de Estado no Brasil em 1964", refere-se ao conjunto de eventos ocorridos nos dias trinta e um de março e primeiro de abril de 1964, no Brasil, que culminaram com um golpe de Estado, encerrando o governo do presidente João Goulart, que havia sido eleito democraticamente.

Os militares, após golpe de 1964, mantiveram o poder político no Brasil por vinte e um anos. No primeiro ano, aproximadamente, os militares formaram uma aliança com a União Democrática Nacional - UDN, partido que tradicionalmente combatia o populismo e almejava o poder há muito tempo. Como afirma Skidmore, "tratava-se de um esforço dos militares para parecerem legítimos a despeito de sua tomada do poder" (1998: 225). Contudo, essa estratégia não foi suficiente para atrair a confiança e o voto da população. Em 1965, os militares impuseram um novo sistema político, criando o bipartidarismo: um partido do governo, Aliança Renovadora Nacional - ARENA -, e um de oposição, Movimento Democrático Brasileiro - MDB. A maioria dos integrantes da extinta UDN migrou automaticamente para a ARENA. Este foi mais um esforço para "legitimar o ilegítimo" (idem).

$\mathrm{Na}$ historiografia brasileira recente, defendese a ideia de que o golpe, bem como a ditadura que este instaurou, não deve ser considerado como exclusivamente militar e sim, civil-militar. Além da elite política de São Paulo, também a burguesia industrial paulista ajudou a conspirar a queda do presidente Goulart. Cinco meses após o golpe militar, a tradicional revista norte-americana Fortune publicava uma longa reportagem na qual narrava a parceria entre o então embaixador dos EUA, Lincoln Gordon, e os empresários paulistas que articularam a conspiração contra o governo de João Goulart3. A parceria entre os militares e os

\footnotetext{
${ }^{3}$ Artigo publicado por Philip Siekman na revista Fortune, edição de setembro de 1964, intitulado "When Executives Turned Revolutionaries" (Quando executivos viraram revolucionários), com o subtítulo: "Uma história ainda não contada: como os empresários de São Paulo conspiraram
}

empresários paulistas, na época, revela uma relação baseada na afinidade ideológica e, principalmente, no interesse econômico, pois, de acordo com Paulo Haddad, na fase inicial do governo militar (entre 1969 e 1971), "São Paulo detinha 40\% do PIB, sendo que o PIB per capita era o dobro do PIB per capita do resto do país. O estado tinha também $52,8 \%$ da capacidade industrial do país" (HADDAD, 2011). Para o pesquisador Jorge José de Melo, o que despertava interesse do empresariado paulista em "Colaborar com esse tipo de estrutura do regime era ter acesso livre aos recursos públicos. Alguns colaboraram ideologicamente [...] mas outros colaboravam para ter acesso mais fácil aos recursos." 4 (nota de rodapé). Recentemente, Rosa Cardoso, membro da Comissão Nacional da Verdade, em entrevista concedida à revista Carta Capital, defende a responsabilização institucional das empresas que apoiaram a ditadura, "Assim, conseguimos mostrar que tratou-se de um golpe civil militar e não apenas militar, uma vez que foi construído por toda uma classe empresarial" 5.

Logo após o endurecimento da repressão contra os opositores do regime, no segundo semestre de 1969, o II Exército, com sede em São Paulo, lançou a Operação Bandeirante (OBAN) - embrião do futuro DOI-CODI (Destacamento de Operações Internas e Centro de Operações de Defesa Interna) - com a finalidade de exterminar os principais opositores ao regime. Como afirma o professor Fábio Konder Comparato, "No Brasil, os grandes empresários não hesitaram em financiar a instalação de aparelhos de terror estatal [...] Ao mesmo tempo, a Federação das Indústrias de São Paulo - FIESP convidou as empresas que a integravam a colaborar no empreendimento" (COMPARATO, 2014).

Neste contexto, verifica-se que dois governadores eram representantes do empresariado paulista: Laudo Natel e Paulo Maluf, enquanto outros dois, Abreu Sodré e Paulo Egydio, saíram dos principais quadros da UDN. Em ambos os casos, dois polos

para derrubar o governo infectado de comunistas do Brasil”. Aversão em inglês está disponível em <https://pt.scribd.com/doc/201734165/Fortunepdf $>$.

${ }^{4}$ Revista Carta Capital [on-line]. Reportagem de por Marsílea Gombata publicada em 15/03/2014. Disponível na Internet: < http://www.cartacapital. com.br/sociedade/comissao-da-verdade-quer-responsabilizar-empresasque-colaboraram-com-a-ditadura-8874.html>.

${ }^{5}$ Idem. 
importantes de apoio ao golpe de Estado e regime autoritário que o sucedeu.

\section{Questão Social: origem e atualidade}

No Brasil, a noção de pobreza é ampla e ambígua, além de supor gradações. A pluralidade de situações que comporta, desafia pesquisadores e sociólogos e estimula a apreensão de uma concepção relativa. De maneira geral, a pobreza é medida com auxílio de indicadores de renda - tendo por base o salário mínimo -, condição de emprego e usufruto de recursos sociais que interferem na determinação do padrão de vida: moradia, saúde, educação, transporte, entre outros. Mesmo possuindo critérios heterogêneos, marcados por uma visão economicista, existe um consenso de que pobres são aqueles que não têm acesso a um mínimo de bens e recursos, seja em situação permanente ou temporária, sendo, por isso, considerados excluídos da riqueza socialmente produzida. Assim, pobres são os desempregados ou subempregados; os que estão incluídos nas faixas mais baixas de renda; aqueles que estão privados dos meios de prover a própria subsistência e que, por isso, não sobrevivem sem ajuda. Maria Carmelita Yazbek entende que a experiência da pobreza "é ainda a experiência da desqualificação dos pobres por suas crenças, seu modo de expressar-se e seu comportamento social, sinais das 'qualidades negativas' e indesejáveis que lhes são conferidas por sua procedência de classe" (1993, p.62).

Tentar entender a problemática vivida hoje no heterogêneo mundo capitalista exige uma reflexão sobre a relação capital e trabalho. Isto é, sem mencionar os indivíduos como sujeitos envolvidos nessa disputa e as desigualdades sociais que dela decorrem, deixa as seqüelas da "questão social" na sociedade contemporânea reduzidas a expressões de uma crise do vínculo social, cujas manifestações devem ser enfrentadas com políticas sociais direcionadas aos setores "mais necessitados".

De modo geral, podemos dizer que a expressão "questão social" começou a ser utilizada na terceira década do século XIX, e surgiu como conseqüência dos impactos causados pela primeira onda industrializante na Europa Ocidental. Dessa forma, entende-se que a "questão social" é um conjunto de problemáticas sociais, políticas e econômicas gerado pelo surgimento da classe operária dentro da sociedade capitalista. Vale ressaltar que sua origem, ligada ao continente europeu, refere-se ao processo de desenvolvimento do próprio capitalismo.

Com a intensificação da exploração do trabalho pelo capital, os trabalhadores passam a manifestar seu descontentamento por via da mobilização, iniciada com o movimento operário de reivindicação de direitos, pressionando o empresariado e o Estado, constituindo-se em uma ameaça real à ordem estabelecida. Esse movimento não se passa sem uma reação por parte da classe dominante como afirma Pastorini: "[...] por outro lado e ao mesmo tempo, se faz presente a intervenção inibidora da burguesia, que buscou impedir o acesso igualitário das classes trabalhadoras ao processo de socialização da política, da riqueza, etc" (2004, p.105).

Diante da incapacidade de garantir o direito ao trabalho, a burguesia procurou uma estratégia que pudesse anular a pressão exercida pela classe trabalhadora. Inicia-se, então, a intervenção de uma instituição aparentemente neutra, mas com poderes de "vigiar" o social. A partir daí, o Estado começou a interferir na relação capital-trabalho, almejando cobrir os riscos que têm conseqüências negativas para o interesse do capital, travestindo sua atuação como uma preocupação com o interesse coletivo. Com isso, as manifestações da "questão social" (fome, doença, miséria, desemprego) consideradas como males incuráveis são entendidas como passíveis de serem amenizadas com a intervenção estatal.

Nesse contexto, as desigualdades sociais não são reduzidas; ao contrário, se agravam. Vários itens da "questão social" atravessaram a história do Brasil: a luta pela terra, o direito de greve, as garantias de emprego, o acesso à saúde, educação, alimentação e habitação, as reivindicações do movimento negro, o problema indígena. Muitos outros itens aparecem em diversos momentos, revelando uma história que pode ser sintetizada nos seguintes termos: "questão social", problema de polícia, problema político, direitos.

\section{Análise de discurso}

Parte-se do princípio, como afirma Eni Puccinelli Orlandi, que a Análise de Discurso ${ }^{6}$

\footnotetext{
${ }^{6}$ Para simplificar a leitura, daqui em diante Análise de discurso passa a ser denominada por AD.
} 
tem como propósito "a compreensão de como um objeto simbólico produz sentidos, como ele está investido de significância para e por sujeitos". Essa compreensão, ainda segundo a autora, "implica em explicitar como o texto organiza os gestos de interpretação que relacionam sujeito e sentido. Produzem-se assim novas práticas de leitura" (2010, p. 26-27). Para Orlandi, os dizeres não são apenas mensagens passíveis de decodificação, mas efeitos de sentidos produzidos em condições determinadas, e que deixa vestígios no modo como se diz,

São pistas que ele aprende a seguir para compreender os sentidos aí produzidos, pondo em relação o dizer com sua exterioridade, suas condições de produção. Esses sentidos têm a ver com o que é dito ali, mas também em outros lugares, assim como com o que não é dito, e com o que poderia ser dito e não foi. Desse modo, as margens do dizer, do texto, também fazem parte dele (2010, p.30).

Não existem sentidos "literais" arquivados em algum compartimento do cérebro e que "aprendemos" a utilizar. A constituição dos sentidos e dos sujeitos se dá em processos, onde coexistem os jogos simbólicos - o que não temos o controle - e o equívoco, por meio do trabalho da ideologia e do inconsciente. Dessa maneira, pode-se afirmar que as visões de mundo se materializam na linguagem em suas diferentes manifestações: a verbal, a visual, a gestual, etc. A maneira de pensar o mundo, numa dada época, subordina-se aos temas e figuras estabelecidos por essas visões de mundo. Assim, a maior parte dos discursos produzidos numa formação social concreta repete esses temas e figuras. Com relação à formação discursiva, Fiorin afirma que,

Temos, então, que considerar a formação ideológica como uma visão de mundo, ou seja, o ponto de vista de uma classe presente numa determinada formação social, e a formação discursiva como o conjunto de temas e figuras que materializam uma dada formação ideológica. (1988, p.14).

Entende-se que o texto é também um lugar de manipulação consciente, onde o sujeito falante organiza recursos de expressão para veicular, da melhor maneira possível, determinados discursos. O sujeito de uma dada formação social tem na formação discursiva a matéria-prima para elaborar seus discursos. No geral, ele reproduz em seus discursos as figuras e os temas presentes nos discursos dominantes de uma dada época, num determinado espaço geográfico. Entende-se, então, que " $\mathrm{O}$ enunciador real sempre vocaliza as formações ideológicas existentes na formação social em que vive" (FIORIN, 1988, p.16).

Embora seja depositário de várias formações discursivas presentes numa formação social concreta - dividida em classes sociais distintas - o enunciador, sendo um ser social, geralmente é suporte apenas da formação discursiva dominante, que materializa a formação ideológica dominante. Não interessa à $\mathrm{AD}$, dessa forma, saber se o enunciador real está ocultando ou revelando, com o discurso, sua posição de classe, pois a análise do discurso não é investigação policial. O foco de interesse da análise é pela ideologia que enunciador, inscrito no interior do discurso, transmite.

Por mais inocente que possa parecer qualquer enunciado pode ter um sentido político. Embora se deva reconhecer que um enunciado aparentemente político pode, dependendo da situação, funcionar apenas como pretexto para referenciar outra coisa que não é política. Assim, tem-se que não é o discurso que é político, "mas a situação de comunicação que assim o torna. Não é o conteúdo que assim o faz, mas é a situação que o politiza" (CHARAUDEAU, 2011, p.40).

De qualquer maneira, como ato de comunicação, o discurso político está mais relacionado aos atores que participam da cena política. Verdadeiro campo de batalha em que se trava uma guerra simbólica, a política visa estabelecer relações de dominação ou pactos de convenção. $\mathrm{O}$ discurso político objetiva, assim, influenciar as opiniões a fim de obter adesões às propostas que defende, ou rejeições aos projetos adversários.

O discurso político não esgota, de forma alguma, todo o conceito político, mas não há política sem discurso. Este é constitutivo daquela. A linguagem é o que motiva a ação, a orienta e lhe dá sentido. A política depende da ação e se inscreve constitutivamente nas relações de influência social, e a linguagem, em virtude do fenômeno de circulação dos discursos, é o que permite que se constituam espaços de discussão, de persuasão e de sedução nos quais se elaboram o pensamento e a ação po- 
líticos. A ação política e o discurso político estão indissociavelmente ligados, o que justifica pelo mesmo raciocínio o estudo político pelo discurso (CHARAUDEAU, 2011, p.39).

Importante lembrar que o discurso não é o lugar da liberdade e da criação. Dessa forma, as formações discursivas determinam o que o indivíduo fala. Evidentemente, existe a possibilidade de o sujeito constituir discursos críticos - diferentes dos discursos dominantes -, visto que o discurso crítico não surge do nada, antes, já está previsto numa formação social.

Outra noção importante no âmbito da análise do discurso é a de "condições de produção" do discurso. As condições de produção do discurso (doravante CP) trazem para o discurso os lugares sociais e suas representações, e também as relações de força e as relações de mundo da sociedade, independente da dimensão contextual - estrita ou ampla. Como afirma Brandão, as CP “constituem a instância verbal de produção do discurso, o contexto histórico-social, os interlocutores, o lugar de onde falam e a imagem que fazem de si, do outro e do referente" (2004, p. 105).

Conforme Orlandi, o sentido estrito das CP refere-se ao contexto imediato da enunciação, enquanto o sentido amplo inclui os contextos sócio-histórico e ideológico. As $\mathrm{CP}$ em sentido amplo abrangem, além do contexto sócio-histórico, também do imaginário produzido pelas instituições, sobre o já-dito, sobre a memória. Para Orlandi, essa "memória do dizer" refere-se ao interdiscurso, ou seja, ao exterior constitutivo do discurso.

O interdiscurso é todo o conjunto de formulações feitas e já esquecidas que determinam o que dizemos. Para que minhas palavras tenham sentido é preciso que elas já façam sentido. E isto é efeito do interdiscurso: é preciso que o que foi dito por um sujeito específico, em um momento particular se apague na memória para que, passando para o "anonimato", possa fazer sentido em "minhas" palavras (ORLANDI, 2010, p. 33-34).

Responsável pelos sentidos que provêm de outro lugar, esse exterior constitutivo revela a necessidade dos movimentos parafrásticos e polissêmicos para a constituição dos sentidos. Entende a autora que o sentido surge a partir de deslocamentos do já-dito, em outras palavras, da memória do dizer. Sobre o interdiscurso, Orlandi (2010) relaciona-o a um eixo de constituição, "um eixo vertical onde teríamos todos os dizeres já ditos - e esquecidos em uma estratificação de enunciados que, em seu conjunto, representa o dizível” (p. 32-33). Já o eixo horizontal - intradiscurso 7 - refere-se à formulação, isto é, "aquilo que estamos dizendo naquele momento dado, em condições dadas" (p. 33). Dessa forma, toda enunciação encontra-se no cruzamento dos dois eixos: o da memória (constituição) e o da atualização do já-dito (formulação).

\section{Sociedade do Espetáculo}

Publicado em 1967, o livro Sociedade do Espetáculo, do pensador francês Guy Debord, denunciava a tirania das imagens e a submissão alienante ao império da mídia. Para ele, os profissionais do espetáculo tinham passado a organizar de maneira consciente e sistemática o império da passividade moderna. Os fundamentos da crítica de Debord são a vida cotidiana e a generalização do fetichismo da mercadoria, que invadiu todos os espaços da vida em sociedade. A mercantilização das relações sociais produz o espetáculo ininterrupto. Nele, o tempo, o espaço, o lazer, a comunicação, a cultura e tudo o mais é perpassado pela alienação. Para Debord, "O espetáculo não é um conjunto de imagens, mas uma relação social entre pessoas, mediada por imagens" (2004, p.14).

No plano das técnicas, a imagem "construída" pode tornar-se a principal ligação do indivíduo com o mundo real, que ele vivenciava por si mesmo, interagindo com as situações que defrontava em qualquer lugar que pudesse ir. Na sociedade espetacular não há mais espaço para vivermos nossas próprias experiências, são os modelos que vivem em nosso lugar: "tudo o que era vivido diretamente torna-se uma representação" (DEBORD, 2004, p.13). As relações humanas são perpassadas pela lógica mercantil, e as pessoas são imersas em imagens que remetem unicamente às mercadorias. $\mathrm{O}$ consumo se apresenta como resposta ao vazio, ao não-lugar em

\footnotetext{
7 Para Maingueneau, intradiscurso "opõe-se ao interdiscurso como as relações entre os constituintes do discurso opõem-se às relações desse discurso com outros" (2000, p. 90).
} 
que as pessoas aprisionadas pelo espetáculo são remetidas. Isso confere à imagem o poder de sustentar qualquer argumentação que se pretende impor, pois no plano da imagem é possível conectar as contradições do mundo, que jamais se reconciliariam na vida real.

Quando o mundo real se transforma em simples imagens, as simples imagens tornam-se seres reais e motivações eficientes de um comportamento hipnótico. O espetáculo como tendência a fazer ver (por diferentes mediações especializadas) o mundo que já não se pode tocar diretamente servese da visão como sentido privilegiado da pessoa humana - o que em outras épocas fora o tato; o sentido mais abstrato, e mais sujeito à mistificação, corresponde à abstração generalizada da sociedade atual (DEBORD, 2004, p.18).

O ser humano imerso na sociedade do consumo tem sua vida e experiências moldadas pelos espetáculos da cultura e da mídia, e nessa condição deixa de ser sujeito ativo de sua própria história e torna-se refém dos espetáculos consumistas. Os indivíduos se distanciam de suas responsabilidades com a vida real, submergindo no mundo da fantasia, irreal. Dessa forma, o espetáculo também é mecanismo de manipulação, servindo de instrumento de pacificação e de despolitização da população.

Em Comentários sobre a Sociedade do Espetáculo, Debord procura definir as três possibilidades de manifestação do poder espetacular:

Em 1967, eu distinguia duas formas, sucessivas e rivais, do poder espetacular: a concentrada e a difusa. Ambas pairavam acima da sociedade real, como seu objetivo e sua mentira. A primeira forma, ao destacar a ideologia concentrada em torno de uma personalidade ditatorial, havia acompanhado a contra-revolução totalitária, fosse nazista ou stanilista. A segunda forma, ao instigar os assalariados a escolherem livremente entre uma grande variedade de mercadorias novas que se enfrentavam, representara a americanização do mundo, assustadora sob certos aspectos, mas também sedutora nos países onde as condições das democracias burguesas de tipo tradicional conseguiram se manter por mais tempo. Uma terceira forma constituiu-se a partir de então, pela combinação das duas anteriores, e na base geral de uma vitória da que se mostrou mais forte, mais difusa. Trata-se do espetacular integrado, que doravante tende a se impor mundialmente (DEBORD, 2004, p.12).

Ainda em Comentários, Debord detalha alguns aspectos do poder espetacular integrado, no qual as características das formas concentrada e difusa do espetáculo se manifestam simultaneamente: “incessante renovação tecnológica, a fusão econômico-estatal, o segredo generalizado, a mentira sem contestação e o presente perpétuo" (2004, p.175).

Entende-se que o conceito de sociedade do espetáculo é um conceito histórico - produto do desenvolvimento do capitalismo -, e sua utilização requer uma análise particularizada, investigando as características das formações econômico-sociais em que se manifesta, além de uma constante atualização das reflexões de Debord.

\section{Ditadura: contexto sócio-político}

No período que antecede o golpe militar cresce a politização da classe operária, e com ela aumentam as greves e a resistência aos desmandos da classe patronal, cada vez mais encastelada e refratária aos aumentos salariais pleiteados. Ao pressionar a classe dominante por mais direitos, os trabalhadores colocam em cheque a estrutura sindical aliançada ao Estado populista.

À direita estavam os tradicionais detentores da riqueza do Brasil. Sua voz principal era a UDN, e dependiam de seus laços com a polícia e o Exército. Entre eles se incluíam os donos de terra e muitos industriais. Seu trunfo era a capacidade dos militares de intervir contra seus inimigos (SKIDMORE, 1998, p.212-213).

Assim os conflitos entre as classes se acirram, e aumenta a pressão política sobre o governo. Em 1964, temendo as massas de trabalhadores, a classe dominante e parte da classe média se aliam aos militares, derrubam o governo João Goulart e instalam a ditadura.

Do ponto de vista político-econômico, Cláudio Coelho entende que, além da disputa pela hegemonia dos principais segmentos da sociedade brasileira durante a ditadura militar, "havia também o projeto de desenvolvimento capitalista sob o controle do capitalismo estrangeiro, com a participação subordinada da burguesia industrial nacional e da oligarquia rural" (2004, p.32). 
No bojo da resistência à ditadura militar que, paradoxalmente, se deu o fortalecimento dos movimentos sociais e entidades da sociedade civil. Nesse período, quando o regime autoritário bloqueava a participação popular na esfera pública e proibia a maioria das manifestações coletivas, as microiniciativas na base da sociedade foram inventando novos espaços de liberdade e novas formas de reivindicação. Proliferam, neste momento, os movimentos comunitários de apoio e ajuda mútua, voltados à defesa de direitos e de luta pelo retorno da democracia. $\mathrm{O}$ encontro da solidariedade com a cidadania, representadas em ações de movimentos sociais, marca esse período com uma dupla proposta: combater a pobreza e combater o governo militar ditatorial.

Em 15 de março de 1967, toma posse Arthur da Costa e Silva - segundo presidente do regime militar -, prometendo promover reformas na estrutura sócio-econômica. Delfim Netto, ministro da Fazenda escolhido por Costa e Silva, é o responsável por elaborar a política econômica que ficou conhecida como "milagre econômico". O Brasil nunca cresceu tanto, exibindo em cinco anos uma média de $8,8 \%$ de crescimento do PIB.

O programa econômico do regime militar brasileiro, de acordo com Rago Filho, foi montado sobre uma política econômica centrada na dinâmica do capital monopolista ${ }^{8}$. Dessa forma, os resultados tornaram-se evidentes:

[...] no quadro da modernização excludente, do capitalismo associado, o inchaço da economia brasileira tornava visível os seus resultados: uma profunda concentração de renda e extrema desigualdade social, conformando a burguesia brasileira, no plano da dinâmica a acumulação do capital, a um papel secundário, cada vez mais subordinado à lógica da internacionalização do capital (RAGO FILHO, 2004, p.148).

Embora os indicadores demonstrassem aumento no nível de renda absoluta na década de 1970, esse aumento ocorria de maneira desigual, "Os benefícios do boom econômico eram, portanto,

\footnotetext{
${ }^{8} \mathrm{Na}$ opinião de Juvêncio Sobrinho, "o 'milagre' foi, durante um curto período, um 'sucesso', especialmente para o capital monopólico interno e externo; já para a maioria da população brasileira, foi, desde o início, um estrondoso fracasso, visto que não poderia, de modo algum, jamais satisfazer suas necessidades mais elementares, já que baseado na superexploração" (2004, p.171).
}

distribuídos de modo muito desigual [...] as fatias do bolo econômico cresceram desigualmente, mas o tamanho absoluto de cada fatia tornava-se maior" (SKIDMORE, 1998, p.253). Quase a metade da população economicamente ativa estava fora do mercado de trabalho formal, desprovida de acesso ao sistema corporativo de saúde, férias e pensões e demais direitos trabalhistas.

A ditadura do capital sobre o trabalho - na fórmula marxiana do trabalho morto que se apodera do vivo - logra o seu máximo objetivo: alcançar altas taxas de crescimento econômico com a elevação da produtividade e a diminuição politicamente forçada do valor da força de trabalho [...] Traduzse, portanto, numa política de extração de maisvalia resultando, concretamente, na forma de superexploração da força de trabalho (RAGO FILHO, 2004, p.149-151).

Reflexo da crise internacional do petróleo, em parte pela desordem no sistema monetário, em 1973 acaba a euforia do milagre econômico brasileiro. Nesse contexto, a política econômica de Delfim Netto não consegue conter o descontrole inflacionário. A população brasileira, com a escassez de produtos, enfrenta longas filas nos supermercados, açougues, etc. As sequelas das "questões sociais" se agravam.

Foram os próprios militares que tomaram a iniciativa da redemocratização, tendo como líder o general Ernesto Geisel, que assumiu a presidência em 1974 após ser eleito indiretamente pelo Congresso. Como afirma Skidmore, depois de uma década de regime autoritário, "a linha moderada queria agora um retorno à democracia, ainda que sob condições cuidadosamente controladas" (1998, p. 257). Ao final de seu governo, Geisel deixava o caminho para a transição preparado. Nas palavras do próprio Geisel, a transição deveria ser "lenta, gradual e segura".

\section{As políticas sociais sob a ditadura militar}

No início (1964-1968), as tentativas da ditadura em legitimar-se politicamente, ampliando uma base de apoio social ao governo, não funcionaram. Logo após a tomada do poder, desencadeou-se um processo repressivo contra atores que poderiam protagonizar enfrentamentos contra os autodenominados "revolucionários". 
Entre eles, "o movimento operário e camponês, as lideranças democráticas mais comprometidas com as forças populares e de esquerda, dentro e fora do aparelho estatal" (NETTO, 2004, p. 36). Em outra vertente, a coalizão vencedora esforçou-se por manter o Congresso ativo - dominado por seus parceiros -, neutralizando as forças contrárias ao governo militar.

Ao Estado pós-64 cabia "racionalizar" a economia: não somente criar o melhor quadro legal-institucional para a concentração e a centralização, mas ainda induzi-las mediante uma ação interna no processo de produção e acumulação. A política econômica estatal, em todos os seus níveis (dos dispositivos tributários, creditícios e financeiros à alocação de capitais diretamente para a produção), deveria voltar-se para acelerar o processo de concentração e centralização (NETTO, 2004, p. 30).

Também na área rural, iniciativas governamentais - fim da estabilidade no emprego e uma política salarial depressiva - distanciavam os trabalhadores do governo militar. Por sua vez, parcela considerável da pequena burguesia urbana começava a sentir os efeitos da desaceleração do crescimento, e diminui seu apoio às medidas do governo, culminando com mais um fraco desempenho eleitoral (1966) dos políticos ligados ao regime militar. Mesmo após a imposição do bipartidarismo, "o governo não colheu evidências de que seus suportes sociais conservavam posições seguras" (NETTO, 2004, p. 36).

As restrições no financiamento das políticas de proteção social, bem como a natureza regulada de acesso aos benefícios vinculada ao emprego assalariado formal (com carteira assinada), limitaram a incorporação de novos segmentos populacionais, a melhoria dos serviços ofertados e o aumento do valor real pago como benefício social. A universalização da proteção social terminou sendo adiada, indicando que a possibilidade de incorporação de novos beneficiados (geralmente mais pobres) representaria, em alguns casos, o abandono voluntário por parte de segmentos mais ricos da população da educação e saúde públicas. Isso motivou a classe média a abandonar não somente a educação fundamental e a saúde pública, buscando atendimento de suas demandas nas ofertas de serviço privado, mas também a deixar de ser parceira na defesa da uni- versalização do sistema de proteção social. Assim, o corporativismo de certas categorias profissionais mais elitizadas - principalmente do funcionalismo estatal - e a meritocracia da escolaridade mais elevada - notadamente das universidades públicas - numa sociedade de analfabetos contaminaram definitivamente as possibilidades de maior articulação de interesses e ação política conjunta na busca por direitos, entre classes operária e média no Brasil.

Durante o período autoritário, consolida-se o Estado assistencial, como compensação ao achatamento salarial, à situação de miséria que se dissemina no país e à forte repressão às manifestações dos trabalhadores. As práticas assistenciais ganham mais estrutura e racionalidade, desenvolvendo-se um aparato estatal que cresce e se burocratiza continuamente, durante todo o período, desmembrando serviços, programas e projetos, seguindo a lógica da segmentação de necessidades, problemas e faixas etárias (MESTRINER, 2001, p. 164).

Apesar disso, nesse período ocorreram conquistas importantes. Por exemplo, em 1923, foi aprovada uma legislação que significou a primeira experiência brasileira de previdência social (caixa de aposentadoria dos ferroviários), que foi ampliada, a partir da década de 1930, para as principais categorias profissionais urbanas (institutos de aposentadorias e pensão). Porém, somente na década de 1960 foi constituído, por intermédio de legislação específica, o fundo próprio de assistência médica e de assistência e aposentadoria para trabalhadores rurais - FUNRURAL -, logo após a unificação dos fundos de aposentadoria e pensão para empregados urbanos por meio do Instituto Nacional de Previdência Social - INPS.

No início dos anos 1970, multiplicam-se os movimentos sociais com o fortalecimento da sociedade civil em oposição ao Estado autoritário. O Brasil iniciava o processo de transição de uma ditadura militar para um regime democrático, implantando a chamada "distensão lenta, segura e gradual" (como os militares costumavam se referir a esse processo). A sociedade brasileira começou a exercer novamente seus direitos constitucionais, suspensos pelo regime autoritário. $\mathrm{O}$ avanço da redemocratização do país, e das eleições diretas para prefeito das capitais e governador tornou mais complexo o relacionamento das organizações de cidadãos com o Estado. 
Além da reivindicação e do conflito, surgiram o diálogo e a colaboração entre as partes.

No final da década de 1970, o fortalecimento do chamado novo sindicalismo no Brasil permitiu não só a retomada da redemocratização do país, mas também a defesa de uma agenda mais ampla, vinculada aos interesses do conjunto dos trabalhadores, tanto rurais como urbanos. Entretanto, sem conseguir aprovar o instrumento do contrato coletivo de trabalho, os sindicatos continuaram a depender da legislação para avançar a proteção social e trabalhista, como aumento do valor real do salário mínimo, introdução do décimo terceiro salário, implantação do salário-família, e outras medidas mais recentes como seguro-desemprego, um terço de férias, redução na jornada de trabalho, etc. Os interesses patronais, da mesma forma, se mostram em grande parte, dependentes da legislação e do poder policial do Estado autoritário: repressão à ação sindical operária, imposição de arrocho salarial, garantia de financiamento de entidades de representação de interesses patronais.

As alianças políticas estratégicas entre os trabalhadores sindicalizados e organizados das grandes empresas e o conjunto de trabalhadores de salário de base - que recebiam o salário mínimo estabelecido pelo governo - foram desfeitas após o longo processo de desvalorização do salário mínimo iniciado pelo regime militar, em 1964. A evolução do piso salarial, bem acima do valor do salário mínimo, para trabalhadores sindicalizados nas grandes empresas, levou esse contingente a abandonar a luta pela elevação do valor real do salário mínimo nacional. Enquanto isso, a maior parte dos trabalhadores sem organização e sindicatos fortes para defender o valor do mínimo nacional, aceitou ampliar a jornada de trabalho (representando horas extras em excesso) e o ingresso da mulher e dos filhos em idade precoce no "mercado de trabalho" para compensar o achatamento da renda familiar.

Apesar da onda ufanista que tomou conta do Brasil durante o regime militar, quando vários setores sociais e políticos dominantes, dentro e fora do aparelho estatal, proclamaram o extraordinário dinamismo da economia do país, o chamado "milagre brasileiro", a sociedade moderniza-se pouco e as relações sociais e políticas desenvolvem-se com dificuldade. Heranças oligárquicas e patrimoniais juntam-se aos interesses dominantes aglutinados em diretrizes governamentais, bloqueando os avanços mais significativos dos direitos sociais, reivindicados por movimentos sociais, organizações sindicais, partidos políticos e outros espaços de atividades sociais e políticas.

No final do período, as condições de vida da maior parte da população são tão precárias, as desigualdades sociais se acentuam tão rapidamente, que suscitam por parte dos trabalhadores a luta pelas condições de reprodução social, pela justiça e pelo direito (MESTRINER, 2001, p. 180).

Dessa forma, devido ao regime autoritário implantado pela ditadura militar, as chamadas reformas civilizatórias do capitalismo ocorridas nas economias centrais foram bloqueadas, justamente nos momentos cruciais da história dos movimentos sociais brasileiros. Ficaram sem solução: a reforma agrária, necessária à redistribuição da concentrada propriedade fundiária; a reforma tributária que tornasse progressiva a estrutura dos impostos, visando atingir principalmente os mais ricos; e a reforma social que possibilitasse a universalização do acesso aos direitos sociais e trabalhistas.

\section{Governadores e sequências discursivas}

Nesta seção, apresentam-se os governadores do Estado de São Paulo, eleitos indiretamente no período compreendido entre 1967 e 1978 - Abreu Sodré, Laudo Natel, Paulo Egydio e Paulo Maluf -, e as sequências discursivas selecionadas dos respectivos discursos de posse, iniciando por uma breve descrição das condições de produção do discurso.

Considerando as condições de produção de discurso, o referente é o discurso de posse do governador do Estado de São Paulo, eleito indiretamente por um colégio eleitoral ou indicado pelo Presidente da República. O locutor é o próprio governador empossado (posição sócio-histórica, de onde tem algo a dizer), e o alocutário é aquele que tem algo a ouvir, considerando sua posição sócio-histórica. O contexto estrito é o momento da enunciação do locutor, ou seja, o discurso de posse de um governador. Como contexto lato pode ser considerado a disputa pela hegemonia dos principais segmentos da sociedade: populistas herdeiros da figura de Getúlio Vargas, 
comunistas e movimentos operários e campesinos à esquerda, e à direita os detentores da riqueza do Brasil, tendo à frente a UDN com seus laços com a polícia e Exército.

A situação de comunicação "posses governamentais" exige do governador empossado uma palavra àqueles que o elegeram, e também à sociedade que por ele será governada. É, portanto, uma situação que se relaciona, de um modo geral, ao domínio discursivo político. Nessa situação, a palavra proferida nos discursos é essencialmente política e a instância na qual ela se realiza também o é, uma vez que esses governadores chegaram ao poder pela vontade de seus pares, quando se tratar de eleição indireta, ou pela força de uma instância superior, neste caso, indicação do presidente da nação. Em nenhum dos dois casos a escolha se deu pela vontade cidadã, criando uma lacuna de legitimidade para o novo governador perante a sociedade. Pressupõe-se, portanto, que todo texto dito utilize elementos linguísticos minuciosamente selecionados pelos produtores desses textos visando certos efeitos de sentido, uma vez que as práticas discursivas constroem a imagem (ethos) dos enunciadores e esses refletem a imagem do "Poder" que representam, usando a linguagem como instrumento de legitimação. O domínio da palavra é fundamental para conferir credibilidade ao discurso e para ratificar o merecimento pela conquista do poder.

O governador Roberto Costa de Abreu Sodré (1918-1999), paulistano, formou-se em direito pela Faculdade do Largo de São Francisco na turma de 1942. Em 1945 foi um dos fundadores da União Democrática Nacional - UDN, tornando-se membro da sua Comissão Executiva Nacional e secretário geral da Executiva Estadual. No âmbito do poder legislativo iniciou sua atuação como deputado estadual, exercendo mandatos sucessivos entre 1951 e 1963. Em 1966 foi um dos fundadores da Aliança Renovadora Nacional - ARENA, quando se instalou o bipartidarismo no Brasil, logo no início da ditadura militar. Foi o primeiro governador do Estado de São Paulo a ser eleito indiretamente, para o período de 1967 a 1970.

O governador Laudo Natel (1920), paulista de São Manuel, formou-se em economia e administração de empresas. Durante vinte e cinco anos foi diretor do Banco Bradesco. Nessa mesma área de atuação foi diretor da Associação Comercial de São Paulo, diretor do Sindicato dos Bancos de São Paulo e presidente da Comissão Bancária do Conselho Monetário Nacional. Entre 1952 e 1970 foi tesoureiro e, depois, presidente do São Paulo Futebol Clube. Foi eleito vice-governador em 1962. Com a destituição de Adhemar de Barros, em 1966, exerceu o resto do mandato, unificando as onze usinas hidrelétricas de São Paulo, que deram origem à Companhia Energética de São Paulo (CESP). Como governador - eleito indiretamente - exerceu mandato de 1971 a 1975.

O governador Paulo Egydio Martins (1928), paulistano, formou-se pela Escola Nacional de Engenharia da Universidade do Brasil, no Rio de Janeiro, em 1951. Foi superintendente do Departamento de Engenharia e, depois, gerente geral da Byington \& Companhia. Iniciou sua carreira pública na esfera federal, quando ocupou o Ministério da Indústria e do Comércio em 1966-1967. Eleito indiretamente governador do Estado de São Paulo, exerceu o cargo de 1975 a 1979.

O governador Paulo Salim Maluf(1931), paulistano, formou-se em engenharia civil pela Escola Politécnica da Universidade de São Paulo, no ano de 1954. Até 1969 atuou na área privada, ocupando funções como: vice-presidente da Serraria Americana Salim Maluf S.A., diretor-superintendente da Loma S.A. Agricultura, Administração e Comércio, diretor-superintendente da Eucatex S.A. Entre 1967 e 1969 foi presidente da Caixa Econômica Federal de São Paulo. Foi Prefeito nomeado da cidade de São Paulo de 1969 a 1971. Neste ano passou a ocupar o cargo de Secretário de Estado dos Transportes, exercendo-o até 1975. Eleito indiretamente Governador do Estado exerceu o mandato de 1979 a 1982.

Sequências discursivas selecionadas a partir dos discursos de posse dos governadores:

[Sodré-1967-1] "Desenvolvimento econômico, - repito para que disso tomem nota as consciências reacionárias e endurecidas, - que deverá convergir para o progresso e o bem-estar de todas as camadas sociais e não apenas, como tem sido, para gáudio das novas classes que se constituíam como clientes favorecidas da injusta repartição da riqueza nacional. Se assim não for, agravar-se-ão as injustiças, gerando-se a desesperança, que impele ao desespero e desfecha, como última etapa, nas ditaduras, quaisquer que sejam as suas colocações doutrinárias". 
[Natel-1971-1] “A atenção a Agricultura igualmente se justifica, em face de seu indiscutível papel como fator de redistribuição de renda, ajuda maior quando associado ao ingente esforço de aumento das exportações em que ora se empenha o governo federal".

[Egydio1975-1] "Graças a essa continuidade de princípios e de ideias, não cessou o esforço pela recuperação econômica, pela melhoria do nível geral de vida e pelo aperfeiçoamento das instituições políticas do país, através destes onze anos em que se desdobrou a ação revolucionária, [...]”".

[Maluf-1978-1] "Ampararei a massa que procura trabalho, onde ela puder usufruir condições de fixação com dignidade de vida".

[Maluf-1978-2] "Temos que zelar pela saúde e bem estar deste povo [...]. Temos de ampliar as suas oportunidades educacionais. Qualificar sua mão-de-obra. Para atender a uma vaga crescente de empregos de melhor nível salarial".

\section{Ditadura: ditos dominantes nos discursos de posse}

Nesta seção serão discutidas as sequências discursivas - recortes - selecionadas a partir do discurso de posse de cada governador eleito indiretamente durante a ditadura militar. A discussão parte da elucidação das condições de produção e ditos dominantes do discurso de posse, apoiada na contextualização político-social do período analisado. As teses da Sociedade do Espetáculo (Debord) conduzem a análise crítica do discurso político.

Nos recortes selecionados, destaca-se a questão da legitimidade dos governantes. Durante a ditadura militar, os governadores paulistas foram indicados ou eleitos indiretamente por uma Assembleia Legislativa cooptada pelos militares. O Poder Executivo foi sendo institucionalizados por meio de eleições indiretas.

A noção de legitimidade, de maneira geral, designa a qualidade ou estado daquele cuja ação está bem fundamentada. Tomar a palavra em uma assembleia, decretar uma lei ou um regulamento, aplicar uma sanção ou dar uma gratificação são atos que vão depender da legitimação do sujeito. Como afirma Patrick Charaudeau "O mecanismo pelo qual se é legitimado é o reconhecimento de um sujeito por outros sujeitos, realizado em nome de um valor que é aceito por todos" (2011, p.65).

$\mathrm{O}$ combate às desigualdades sociais, principal argumento utilizado pelos governadores nos discursos de posse, condiciona o enfrentamento das questões sociais ao desenvolvimento econômico do país, vide [Sodré-1967-1], [Natel-1971-1] e [Egydio-1975-1]. Enquanto em [Maluf-1978-1] e [Maluf-1978-2] a preocupação maior é a qualificação de mão de obra para atender a demanda crescente das grandes empresas. Dessa forma, percebe-se que o que os discursos de posse no período da ditadura mostram vem sempre isolado do ambiente real e do passado das coisas - não convém discutir a origem, nem como a miséria se perpetua. Esse é o discurso espetacular que faz calar a sociedade e torna secreto tudo o que não convém.

Primeiro governador paulista indicado pelo regime militar - não eleito democraticamente -, Abreu Sodré deixa claro a existência de uma classe privilegiada que se apropria "injustamente" da riqueza produzida no país. Expõe também o receio de um agravamento das injustiças, que "impele ao desespero e desfecha, como última etapa, nas ditaduras [...]" [Sodré-1967-1]. Com isso, Sodré revela o temor em relação às massas trabalhadoras, alijadas do contexto político após a derrubada do governo João Goulart e perseguição às forças políticas comprometidas com reformas estruturantes no período pré-golpe militar. Contrariamente, o não-dito nesse discurso oculta o apoio maciço das classes dominantes e seus representantes políticos - entre eles, Sodré - aos militares, num claro projeto de conservação do perverso sistema de exploração capitalista.

Como afirma Debord, um grande passo para efetivar o processo da dominação espetacular era "fazer sumir o conhecimento histórico geral; e, em primeiro lugar, quase todas as informações e todos os comentários razoáveis sobre o passado recente" (2004: 176). Imprescindível manter um discurso único e hegemônico capaz de anular as vozes discordantes. A ignorância do que acontece é organizada com habilidade e aquilo que conseguiu se fazer conhecer é rapidamente levado ao esquecimento sob pena de quebrar a harmonia estabelecida pelo dominador. "O mais importante é o mais oculto" (DEBORD, 2004, p.177). 
Laudo Natel, em seu discurso de posse segue a cartilha do governo militar: primeiro estimular crescimento econômico, e depois enfrentar a questão social. Ex-diretor da Associação Comercial de São Paulo, instituição que apoiou o golpe militar e colaborou com o regime autoritário que o sucedeu, Laudo Natel, em sua segunda passagem pelo governo de São Paulo, afirma que daria maior atenção à Agricultura, justificando: "em face de seu indiscutível papel como fator de redistribuição de renda" [Natel-1971-1]. Após sete anos, os militares ainda tentavam legitimar sua permanência no poder, enfrentando resistência mesmo entre antigos aliados. Neste sentido, o discurso de Laudo Natel mostra alinhamento com a política econômica dos militares: "ingente esforço de aumento das exportações em que ora se empenha o governo federal" [Natel-1971-1].

Na posse do governador Paulo Egydio, o Brasil enfrentava um período de depressão econômica - pós-milagre econômico brasileiro. Seu discurso de posse exalta o governo militar: "Graças a essa continuidade de princípios e de ideias", tentando também reanimar as classes trabalhadoras: "não cessou o esforço pela recuperação econômica, pela melhoria do nível geral de vida". Seguindo seus predecessores, continua a busca pela legitimação do golpe de Estado: "através destes onze anos em que se desdobrou a ação revolucionária" [Egydio1975-1].

Quando falamos não revelamos apenas o conteúdo de nosso pensamento, nosso posicionamento ideológico ou nossa opinião. O que dizemos é fruto da relação que estabelecemos conosco e que pode ser percebida pelos outros. No recorte: "Ampararei a massa que procura trabalho, onde ela puder usufruir condições de fixação com dignidade de vida" [Maluf-1978-1], pode-se questionar: e aos que não procuram trabalho, o que o governo de Paulo Maluf reservava? O não-dito nesse discurso omite a super-exploração do trabalho, decorrida do achatamento do salário imposto pelo regime autoritário, do qual Maluf fazia parte. Rago Filho dá a medida do pensamento conservador dominante:

A essa grande massa de desempregados, que vivia na órbita periférica do alto consumo dos mercados hiper-desenvolvidos, era atribuído o estigma de inúteis, preguiçosos, sem qualificação profissional, sem educação aprimorada (2004, p.154).
Em clara ausência de sintonia com as classes trabalhadoras, em plena crise econômica, o governador Paulo Maluf, através do não-dito em seu discurso de posse, tenta imputar o declínio da economia à falta de qualificação da mão-de-obra e ausência de escolaridade da população. A preocupação maior era formar profissionais para a indústria, "Para atender a uma vaga crescente de empregos de melhor nível salarial" [Maluf-1978-2].

Mesmo investindo num projeto de desenvolvimento capitalista, a ditadura militar, atada às heranças oligárquicas e patrimoniais, não consegue avançar na modernização da sociedade, convivendo simultaneamente uma sociedade do consumo que se desenvolve, e um autoritarismo arcaico, centralizador do poder político. Para Debord, embora o espetáculo na sua forma concentrada pertença essencialmente ao capitalismo burocrático, ele pode ser apropriado como técnica do poder estatal por "economias mistas mais atrasadas". Cláudio Coelho entende que essa definição - "economias mistas mais atrasadas" poderia aplicar-se ao estágio político-social em que o Brasil se encontrava no período da ditadura militar:

Nesse período havia a presença simultânea de um Estado economicamente intervencionista e promotor do "desenvolvimento", a serviço da burguesia brasileira e multinacional, que concentrava o exercício do poder político [...], e de uma sociedade de consumo em processo de constituição promotora do culto das mercadorias e difusão social (especialmente pela Rede Globo de Televisão) das práticas espetaculares (2006, p. 21-22).

Por fim, todo aparato de sustentação do espetáculo, envolvendo as mídias prosperam sem entraves no período. Enquanto isso, mecanismos de controle social e a busca de conservação do poder transformam governos em extensões do comando militar, perpetuando métodos arbitrários e desmandos de toda sorte. Quando o poder espetacular atinge o estágio integrado, a concentração do poder convive harmonicamente com os mecanismos de difusão do espetáculo.

Dessa forma, os ditos dominantes sobre a questão social nos discursos de posse dos quatro governadores no período, refletindo as condições de produção do discurso, revelam intenções e 
necessidades (CP sentido estrito): legitimar o regime militar; desenvolver a economia do país; reprimir os movimentos sociais de reivindicação. Os discursos também indicam uma disputa pela hegemonia dos principais segmentos da sociedade brasileira (CP em sentido amplo). Dessa forma, os militares e seus apoiadores civis realizaram uma contra-revolução na tentativa de bloquear o avanço das classes autodenominadas "revolucionárias" - movimento operário; ligas camponesas; lideranças democráticas de esquerda - dentro e fora da máquina estatal. Com isso, o golpe militar impediu o aprofundamento da discussão sobre o enfrentamento da questão social no Brasil.

\section{Considerações finais}

O discurso de superação das desigualdades sociais como consequência do desenvolvimento da economia faz parte da cena política brasileira no período analisado. Porém, o contexto sócio-político e os interesses intrínsecos dos protagonistas - governadores - imprimem conotações diferenciadas, ou mesmo antagônicas aos discursos de posse dos governadores, revelando posicionamentos políticos e disputas entre classes sociais.

Apesar do reconhecimento da questão social estar presente nesses discursos de posse, vários itens da questão social atravessaram a história do Brasil e persistem como problema. Durante a ditadura militar, os ditos dominantes revelam governos centralizadores e autoritários que enfrentam as manifestações da sociedade por melhores condições de vida como problema de polícia.

Uma interpretação livre das teses de Debord, utilizadas na análise crítica dos discursos de posse no período analisado, aponta para os três estágios do poder espetacular: concentrado, difuso e integrado. Na ditadura militar, a concentração do poder e a utilização da força no enfrentamento das demandas da população, permitem analisar o período utilizando as teses do poder espetacular concentrado. Embora exista uma supressão da democracia, não há ruptura com a implantação da sociedade do consumo. Ao contrário, a propaganda e a publicidade prosperam como poderosas ferramentas na difusão da ideologia dominante do consumo, e o cenário político-econô- mico se aproximam do que Debord chamou de poder espetacular difuso.

Este trabalho procurou exemplificar a potencialidade crítica das teses de Debord quando contextualizadas em uma sociedade determinada. Para tanto, utilizou-se a análise do discurso para identificar os ditos dominantes em um dado contexto sócio-histórico. Tanto a contextualização pode ser ampliada, quanto à análise dos sentidos presentes nos discursos de posse pode explorar variantes não tratadas aqui. Fica, então, a possibilidade de futuros trabalhos.

\section{Referências}

BRANDÃO, Helena H. N. Introdução à análise do discurso. $2^{\mathrm{a}}$. ed. São Paulo: Unicamp, 2004.

CHARAUDEAU, Patrick. Discurso político. São Paulo: Contexto, 2011.

COELHO, Cláudio N. P. A indústria cultural, a publicidade e a consolidação da hegemonia burguesa no Brasil. Communicare, v. 4, n. 2, São Paulo: Cásper Líbero, p. 2939, 2004.

. Em torno do conceito de sociedade do espetáculo. In COELHO, Cláudio N. P. e CASTRO, Valdir J. (Orgs). Comunicação e sociedade do espetáculo. São Paulo: Paulus, 2006.

COMPARATO, Fábio Konder. Compreensão histórica do regime empresarial-militar brasileiro. Brasil de fato: uma visão popular do Brasil e do mundo, São Paulo, 11 mar. de 2014. Disponível em <http://www.brasildefato.com.br/ node/27692>, acesso em 22/04/2014.

DEBORD, Guy. A sociedade do espetáculo. $1^{\mathrm{a}}$. ed. $5^{\mathrm{a}}$. reimpr. Rio de Janeiro: Contraponto, 2004.

FIORIN, José Luiz. O regime de 1964: discurso e ideologia. São Paulo, Atual, 1988.

HADDAD, Paulo R. São Paulo na economia brasileira, $\mathbf{O}$ Estado de São Paulo, Caderno de economia, São Paulo, 17 de jun. 2011. Disponível em: <http://www.estadao. com.br/ noticias/impresso,sao-paulo-na-economiabrasileira,733468,0.htm>, acesso em 22/10/2014.

JUVÊNCIO SOBRINHO, Maria G. O ser e ir sendo capitalismo brasileiro: algumas reflexões. Communicare, v. 4, n. 2, São Paulo: Cásper Líbero, p. 157-174, 2004.

MAINGUENEAU, Dominique. Termos-chave da análise do discurso. Belo Horizonte: UFMG, 2000.

MESTRINER, Maria Luiza. O Estado entre a Filantropia e a assistência Social. São Paulo: Cortez, 2001. 
NETTO, José Paulo. Ditadura e serviço social: uma análise do serviço social no Brasil pós-64. 7a . ed. São Paulo: Cortez, 2004.

ORLANDI, Eni Puccinelli. Análise de discurso: princípios e procedimentos. 9a . ed. Campinas: Pontes Editores, 2010.

PASTORINI, Alejandra. A categoria "Questão Social” em debate. São Paulo: Cortez, 2004.

RAGO FILHO, Antônio. A lógica perversa do capital atrófico. Communicare, v. 4, n. 2, São Paulo: Cásper Líbero, p. 145-156, 2004.

SKIDMORE, Thomas E. Uma história do Brasil. Rio de Janeiro: Paz e Terra, 1998.

SOARES, Laura Tavares. O desastre social. Rio de Janeiro: Record, 2003.

YAZBEK, Maria Carmelita. Classes subalternas e assistência social. $4^{\text {a }}$. ed. São Paulo: Cortez, 1993.

Submissão: $15 / 07 / 2013$

Aprovação: 06/2014 